\title{
Mini Review
}

\section{Vision in the Hearing-Impaired: Enhanced or Deprived?}

\author{
Jaikishan Jayakumar, PhD* \\ Senior Project Advisor, Center for Computational Brain Research, Indian Institute of Technology, Madras Guindy, Chennai 600036, India \\ *Corresponding author \\ Jaikishan Jayakumar, PhD \\ Senior Project Advisor, Center for Computational Brain Research, Indian Institute of Technology, Madras Guindy, Chennai 600036, India; Tel. +9I 44 2257 892 I; \\ E-mail: jaikishan.jayakumar@gmail.com
}

\section{Article information}

Received: March 4 $4^{\text {th }}, 2019$; Revised: March 18 ${ }^{\text {th }}, 2019$; Accepted: March 19th 2019 ; Published: March $25^{\text {th }}, 2019$

Cite this article

Jayakumar J. Vision in the hearing-impaired: Enhanced or deprived? Neuro Open J. 20I9; 6(I): 6-9. doi: I0.17/40/NOJ-6-I30

\section{ABSTRACT}

By definition, the hearing-impaired lack one functioning sensory channel that transmits information to the brain. What effect does this have on the perceptual systems of the brain is the subject of the review. There are currently two hypotheses on this matter: The perceptual deficit hypothesis that states that lack of a functioning sensory input affects the development and maturation of other sensory channels and results in the impaired functioning of our senses. The second is the perceptual compensation hypothesis which states that when one sensory system is affected, the processing resources within the brain are reallocated to the other sensory system resulting in an enhancement of the other systems. This review is about both these hypotheses and attempts to answer the question if the hearing-impaired can really "see "better. We highlight the important findings from both these hypotheses and provide growing evidence for the perceptual compensation hypothesis.

\section{Keywords}

Hearing-impaired; Vision; Perceptual deficit; Perceptual compensation; Audition.

\section{INTRODUCTION}

$\mathrm{W}$ e perceive our environment using a wide variety of senses including vision and audition and rely upon them individually or in combination to make sense of our world. Conventional neuroscience dictates that the neuroplastic processes within the brain allow for the efficient use of its available resources. This results in the phenomenon that is not necessarily beneficial, for example the expansion of somatosensory maps following limb amputation results in spurious perceptual events known as "phantom limb pain"1 or untreated amblyopia results in the profound loss of visual acuity. ${ }^{2}$ How this process works during the complete loss of sensory information from one modality is still a topic of debate. One theory suggests that developmentally the loss of one sense, say hearing, will adversely affect other senses as well, this is known as the perceptual deficit hypothesis. On the other hand, there is mounting evidence that when one sensory system affected, there is the reallocation of resources to another system resulting in an enhancement of other sensory systems. This is termed as the perceptual compensatory hypothesis and is believed to be the direct result of the cross-modal plasticity properties of the brain. In this mini-review, we aim to explore both these hypotheses.

\section{The Perceptual Deficit Hypothesis}

The first hypothesis states that a significant deficit in one sensory modality affects the development and organization of the other sensory systems. This is termed as the perceptual deficit hypothesis. In the case of hearing-impaired, the perceptual deficit hypothesis predicts hearing-impaired individuals will exhibit poorer visual and tactile perceptual performance. ${ }^{3}$ The secondary assumption is that the lack of one sensory input adversely affects the complex tasks such as language which needs significant interaction between the different senses. ${ }^{4}$

The hypothesis mainly came about because of the increased prevalence of vision-related abnormalities in the congenitally hearing-impaired that has been reported in the literature. $^{5,6}$ The seminal studies by Pollard and Neumaier ${ }^{5}$ and by Mohindra ${ }^{6}$ where visual problems were found to be much more in hearing-impaired school going children as compared to normal school going children. There is some evidence supporting this hypothesis as the hearing-impaired perform significantly worse 
than hearing children in basic threshold perceptual tasks. ${ }^{7}$

\section{The Perceptual Compensatory Hypothesis}

The perceptual compensatory hypothesis originated as a direct result of Neville et $\mathrm{al}^{8}{ }^{8}$ who used visually evoked potentials in hearing-impaired individuals and showed an enhanced recorded signal which implies that the lack of auditory experience somehow reorganized to enhance the visual processing abilities. This work has since been repeated using a wide variety of techniques including electroencephalogram (EEG); ${ }^{9}$ magnetoencephalography; ${ }^{10}$ functional magnetic resonance imaging ${ }^{11,12}$ with similar findings. But the perceptual implications of this enhanced signal are still unclear.

\section{DISCUSSION}

\section{Basic Visual Thresholds in the Hearing-Impaired}

One of the first studies in determining the differences in brightness sensitivity between the hearing-impaired and the hearing individuals was performed by Bross et al. ${ }^{13}$ They revealed no significant differences between the hearing-impaired and hearing individuals. Similar results were obtained by Bross and Saurwein ${ }^{14}$ for visual flicker thresholds. This is an indirect contradiction to the compensatory hypothesis.

Other parameters including contrast sensitivity ${ }^{10}$ or both center and periphery ( $2 \mathrm{deg}$ around fixation) $)^{15}$ (see also, Bavelier et $\mathrm{al}^{11,12}$ for further evidence of comparable luminance change detection in hearing-impaired and hearing individuals). Interestingly, Stevens and Neville ${ }^{15}$ showed that the hearingimpaired exhibited an enlarged field of view (about $196 \mathrm{~cm}^{2}$ ) with respect to hearing controls $\left(180 \mathrm{~cm}^{2}\right)$, in a kinetic perimetry task.

Performance of the hearing-impaired in motion discrimination task shows that there are no significant differences in the performance of hearing-impaired and hearing individuals other than a small shift in the preferred hemifield, where the hearingimpaired preferred the right field compared with the left field. ${ }^{16-18}$ Temporal perceptual thresholds for any eccentricities and stimuli time or order showed any differences in the performances of the hearing-impaired when compared with hearing individuals. . $^{14,19,20,21}$

\section{Visual Performance in the Hearing-Impaired? Sensitivity vs Reactivity}

If the hearing-impaired do not show any differences in the various visual discrimination tasks with no evidence of either worse performance (discrediting the perceptual deficit hypothesis) or enhanced (against the perceptual compensation hypothesis), is there any evidence of cross-modal plasticity within the brains of the hearing-impaired and if so what is the behavioral implications of it?

The seminal study by Loke and Song, ${ }^{22}$ was among the first to answer this question. They compared 20 congenital or early- hearing-impaired high school students with 19 hearing controls, and by measuring the reaction times for a simple detection task at either fixation $\left(0.5^{\circ}\right)$, or in the visual periphery $\left(25^{\circ}\right)$, they were able to show that the hearing-impaired responded faster than hearing controls (85 ms on average), but selectively for targets appearing at peripheral locations. The differences in the central fixation did not reach statistical significance $(38 \mathrm{~ms})$. This result was later confirmed by ${ }^{23}$ who not only showed that the simple detection of one shape from the other was faster for the hearing-impaired than hearing participants (70 $\mathrm{ms}$ on average); but also, the simple detection and subsequent discrimination of the peripheral shapes to be faster in the hearing-impaired than hearing participants $(56 \mathrm{~ms})$.

Manipulation of attentional mechanisms by the classical cue-target paradigm ${ }^{24}$ has shown that the visual attentional process can be redirected in the hearing-impaired individual. ${ }^{25}$ This interpretation is further supported by Colmenero et $\mathrm{al}^{26}$ who used a task of pressing key "O" appeared on the computer screen. The target appeared for $150 \mathrm{~ms}$, at $20^{\circ}$ of eccentricity to the left or the right of central fixation and was preceded by a vertical mark delivered at the exact target location (valid condition, 53\% of the trials), on the opposite side with respect to the target (invalid condition, $13 \%$ of the trials) or on both sides (neutral condition, $33 \%$ of the trials). Stimulus onset asynchrony (SOA) between the cue and the target varied between 125-250 ms. Hearing-impaired participants were faster than hearing control at detecting the target (43 $\mathrm{ms}$ on average) in this task which involves evoking the exogenous and endogenous attentional mechanism and the interpretation was that the attentional mechanisms including inhibition of return (IOR), ${ }^{27}$ which happens as a result of prior location already attended to in the task are somewhat less enduring in the hearing-impaired than in the hearing controls.

Flanker interference tasks, which measure the allocation of attentional resources in the visual scene, have shown that there is a larger interference of distractors in the periphery in the hearingimpaired than the hearing individuals. ${ }^{28-31}$ These differences only serve to indicate that the allocation of visual attention resources is quite different in the periphery of hearing-impaired individuals as compared with hearing controls, most likely as a result of crossmodal plasticity in the brain.

The above-mentioned findings indicate that the visual abilities demonstrated in the hearing-impaired do not show any trends towards either an enhancement or suppression. This may be because of a few reasons namely, 1) hearing impairment, by definition, consists of a multitude of factors which cannot be classified as one condition. ${ }^{32}$ 2) the definition of the periphery, where the hearing-impaired show enhancement in their reactivity is often muddled. The range of periphery defined in various papers ranges from 1 degree from fixation onwards (for e.g. 8 degrees from fixation in). ${ }^{9}$

\section{CONCLUSION}

The past 50 odd years of research on visual cognition of hearingimpaired individuals have not given a clear answer as to whether 
the hearing-impaired see better. However, there is certainly a better reactivity rather than threshold enhancement in the hearingimpaired particularly in complex visual tasks such as visual attention. This fact and the related findings provide circumstantial evidence at the least towards the compensatory hypothesis. The role that this peripheral attentional resource enhancement can further be considered as a compensatory mechanism for the allocation of attentional resources which are much more efficient in audiovisual integrative conditions.

\section{REFERENCES}

1. Ramachandran VS, Hirstein W. The perception of phantom limbs. The D. O. Hebb lecture. Brain. 1998; 121(9): 1603-1630.

2. Webber AL, Wood J. Amblyopia: Prevalence, natural history, functional effects and treatment. Clin Exp Optom. 2005; 88(6): 365375.

3. Myklebust HH. The Psychology of Deafness: Sensory Deprivation, Learning, and Adjustment. Great Britain, USA: Grune \& Stratton. 1964.

4. Furth HG. Thinking without Language: Psychological Implications of Deafness. New York, NY, USA: Collier-Macmillan. 1966.

5. Pollard G, Neumaier R. Vision characteristics of deaf students. American Annals of the Deaf. 1974: 740-746.

6. Mohindra I. Vision profile of deaf children. Am J Optom Phys Opt. 1976; 53(8): 412-419.

7. Quittner AL, Leibach P, Marciel K. The impact of cochlear implants on young deaf children: New methods to assess cognitive and behavioral development. Arch Otolaryngol Head Neck Surg. 2004; 130(5): 547-554. doi: 10.1001/archotol.130.5.547

8. Neville HJ, Schmidt A, Kutas M. Altered visual-evoked potentials in congenitally hearing-impaired adults. Brain Res. 1983; 266(1): 127-132.

9. Neville HJ, Lawson D. Attention to central and peripheral visual space in a movement detection task: An event related potential and behavioral study: II. Congenitally hearing-impaired adults. Brain Res. 1987; 405(2): 268-283.

10. Finney EM, Dobkins KR. Visual contrast sensitivity in hearingimpaired versus hearing populations: Exploring the perceptual consequences of auditory deprivationand experience with a visual language. Brain Res Cogn Brain Res. 2001; 11(1): 171-183.

11. Bavelier D, Tomann A, Hutton C, et al. Visual attention to the periphery is enhanced in congenitally hearing-impaired individuals. J Neurosci. 2000; 20(17): RC93.

12. Bavelier D, Brozinsky C, Tomman A, Mitchell T, Neville H, Liu $\mathrm{GH}$. Impact of early hearing-impairedness and early exposure to sign language on the cerebral organization for motion processing. J Neurosci. 2001; 21(22): 8931-8942.

13. Bross M. Response bias in hearing-impaired and hearing subjects as a function of motivational factors. Perceptual Motor Skills. 1979; 3: 779-782.

14. Bross M, Sauerwein H. Signal detection analysis of visual flicker in hearing-impaired and hearing individuals Perceptual Motor Skills. 1980; 51: 839-843.

15. Stevens C, Neville H. Neuroplasticity as a double-edged sword: deaf enhancements and dyslexic deficits in motion processing. $J$ Cogn Neurosci.2006; 18(5): 701-714. doi: 10.1162/jocn.2006.18.5.701

16. Bosworth RG, Dobkins KR. Left-hemisphere dominance for motion processing in hearing-impaired signers. Psycho Sci.1999; 10: 256-262. doi: 10.1111\%2F1467-9280.00146

17. Bosworth RG, Dobkins KR. The effect of spatial attention on motion processing in hearing-impaired signers, hearing signers, and hearing nonsigners. Brain Cogn. 2002; 49(1): 152-169. doi: 10.1006/brcg.2001.1497

18. Brozinsky CJ, Bavelier D. Motion velocity thresholds in hearing-impaired signers: Changes in lateralization but not in overall sensitivity. Brain Res Cogni Brain Res. 2004; 21(1): 1-10. doi: 10.1016/j.cogbrainres.2004.05.002

19. Poizner H, Tallal P. Temporal processing in hearing-impaired signers. Brain Lang. 1987; 30(1): 52-62.

20. Nava E, Bottari D, Zampini M, Pavani F. Visual temporal order judgment in profoundly hearing-impaired individuals. Exp Brain Res. 2008; 190(2): 179-188. doi: 10.1007/s00221-008-1459-9

21. Heming JE, Brown LN. Sensory temporal processing in adults with early hearing loss. Brain Cogn. 2005; 59(2): 173-182. doi: 10.1016/j.bandc.2005.05.012

22. Loke WH, Song S. Central and peripheral visual processing in hearing and nonhearing individuals. Bull Psych Soc.1991; 29(5): 437440. doi: 10.3758/BF03333964

23. Reynolds HN. Effects of foveal stimulation on peripheral visual processing and laterality in hearing-impaired and hearing subjects. Am J Psych. 1993; 106(4): 523-540.

24. Posner M. Orienting of attention. Q J Exp Psychol. 1980; 32(1): $3-25$.

25. Parasnis I, Samar VJ. Parafoveal attention in congenitally hearing-impaired and hearing young adults. Brain Cogn. 1985; 4(3): 313-327.

26. Colmenero JM, Catena A, Fuentes LJ, Ramos MM. Mechanisms of visuo-spatial orienting in hearing-impairedness. Eur J Cogn. 
2004; 16: 791-805. doi: 10.1080/09541440340000312

27. Klein RM. Inhibition of return. Trends Cogni Sci. 2000; 4: 138147. doi: 10.1016/S1364-6613(00)01452-2

28. Proksch J, Bavelier D. Changes in the spatial distribution of visual attention after early hearing-impairedness. J Cogn Neurosci. 2002; 14(5): 687-701. doi: 10.1162/08989290260138591

29. Sladen D, Tharpe AM, Ashmead DH, Grantham DW, Chun MM. Visual attention in hearing-impaired and normal hearing adults: Effects of stimulus compatibility. I Speech Lang Hear Res. 2005; 48(6): 1529-1537. doi: 10.1044/1092-4388(2005/106)
30. Chen Q, Zhang M, Zhou X. Effects of spatial distribution of attention during inhibition of return IOR on flanker interference in hearing and congenitally hearing-impaired people. Brain Res. 2006; 1109(1): 117-127. doi: 10.1016/j.brainres.2006.06.043

31. Dye MWG, Baril DE, Bavelier D. Which aspects of visual attention are changed by hearing-impairedness? The case of the attentional network test. Neuropsychologia. 2007; 45(8): 1801-1811. doi: 10.1016\%2Fj.neuropsychologia.2006.12.019

32. Bavelier D, Dye MWG, Hauser PC. Do hearing-impaired individuals see better? Trends Cogn Sci. 2006; 10(11): 512-518. doi: 10.1016\%2Fj.tics.2006.09.006 